\title{
CRIANÇAS MIGRANTES E O DIREITO À EDUCAÇÃO: LEITURAS E CONVERSAS COM EQUATORIANOS NA ATUAÇÃO VOLUNTÁRIA DO GRUPO DIASPOTICS
}

\author{
Immigrant children and the right to education: readings and dialogues \\ with Ecuadorians during the DIASPOTICS's voluntary work
}

\author{
Adriana Maria Assumpção* \\ João Paulo Rossini Teixeira Coelho**
}

\begin{abstract}
Resumo. Este artigo foi motivado pela conversa com um menino equatoriano de sete anos, no qual ele narra que ouviu de sua professora que não aprende a ler porque sua mãe se comunica com ele em espanhol. Nossas inquietações surgiram em meio ao trabalho desenvolvido pelo grupo DIASPOTICS - Migrações Transnacionais \& Comunicação Intercultural com migrantes equatorianos em Copacabana. O objetivo deste texto é refletir sobre a integração de crianças migrantes e seu direito à educação, tendo como cenário empírico o trabalho com esse grupo de crianças matriculadas em duas escolas públicas do Rio de Janeiro. A partir do trabalho de campo realizado, apontamos a necessidade de maior reflexão sobre integração e educação como construção de saberes com todos os atores envolvidos.
\end{abstract}

Palavras-chave: crianças imigrantes; equatorianos; direito à educação; integração.

\begin{abstract}
This article was motivated by a conversation with a seven-yearold Ecuadorian boy, in which he tells he heard from his schoolteacher that he can't learn how to read in Portuguese because his mother communicates with him in Spanish. Our concerns have arisen during the work done by the group DIASPOTICS - International Migrations \& Intercultural Communication with Ecuadorian migrants at Copacabana. The objective of this work is to meditate on migrant integration, having as an empirical scenario the voluntary work with this group of children enrolled in two public schools in Rio de Janeiro. As a conclusion of our field work we indicate the need for reflection on integration and education as a construction of knowledge with all the parts involved in these processes.
\end{abstract}

Keywords: immigrant children; Ecuadorians; right to education; integration.

Professora e pesquisadora da Universidade Estácio de Sá. Membro do grupo DIASPOTICS/UFRJ. Rio de Janeiro, RJ, Brasil. E-mail: professoraadrianaassumpcao@gmail.com. Orcid: https://orcid. org/0000-0002-5570-7877.

** Mestrando Erasmus Mundus+ MITRA: Migrations Transnationales, Université de Lille 3. Membro do grupo DIASPOTICS/UFRJ. Rio de Janeiro, RJ, Brasil. E-mail: jprossini96@gmail.com. Orcid: https://orcid.org/0000-0003-4643-726X. 
"Eu vou para o Equador, deixar o cabelo crescer, e lá eu vou aprender a ler" (Menino equatoriano de sete anos)

\section{Considerações iniciais}

Este artigo tem como objetivo refletir sobre a integração das crianças equatorianas nas escolas públicas onde estudam, dando destaque a falas proferidas por elas e por suas mães ao longo do projeto que é realizado pelo grupo DIASPOTICS - Migrações Transnacionais \& Comunicação Intercultural.

O cenário empírico desta pesquisa se constitui no espaço onde realizamos ação voluntária com as crianças e suas famílias, na Praia de Copacabana, na cidade do Rio de Janeiro. O público dessas atividades é heterogêneo, englobando crianças de dois a nove anos, com origem no Equador e em Angola. O local foi escolhido por se tratar do espaço de trabalho das famílias migrantes, que atuam como vendedores ambulantes, e também por ser onde ficam seus filhos durante o dia e parte da noite.

No presente estudo, o recorte de pesquisa está no grupo de equatorianos, em virtude da questão que envolve o bilinguismo e sua dinâmica particular no processo formal de aprendizagem realizado no Brasil. É premente considerar a integração dessas pessoas como ponto fundamental nesta discussão, pois as dificuldades são inúmeras no que diz respeito ao estudante, mas também em relação à equipe pedagógica da instituição escolar que o recebe.

Nas ações realizadas com as crianças equatorianas desenvolvemos atividades com leituras de textos literários e organizamos ações com caráter pedagógico e lúdico. Busca-se, também, contribuir nas práticas de leitura e escrita em português, entendendo que isso pode ajudar no processo de aprendizagem dos menores na escola. No que diz respeito às famílias, orientamos na condução para a matrícula escolar e participamos de algumas reuniões de pais, atuando como intérpretes na comunicação entre as responsáveis e as professoras.

Concomitantemente, é feito acompanhamento dos trabalhos escolares, os chamados "deveres de casa", por meio do aplicativo de mensagens WhatsApp ${ }^{1}$, em virtude da impossibilidade de realizar encontros presenciais diários. Essa prática foi pensada em função da dificuldade de acesso a um local apropriado para realizar as tarefas escolares e, além disso, por conta do horário em que as mães usualmente realizam as mesmas com as crianças. Normalmente, as famílias chegam em casa por volta de $21 \mathrm{~h}$ após um dia de

1 Os "deveres de casa" muitas vezes não têm seus enunciados compreendidos pelas famílias e, por esse motivo, servimos de intérpretes. 
trabalho, em um local de moradia de difícil acesso, pois residem na favela Pavão-Pavãozinho, localizada também em Copacabana.

As falas destacadas no texto se referem aos sentidos que situações cotidianas trazem para as vivências individuais desses sujeitos. Suas declarações estão carregadas de elementos que nos mostram alguns dos problemas sociais que eles vivem, como a situação de vulnerabilidade em relação à educação, à comunicação em português e à sua moradia. Os depoimentos dos equatorianos permitem fazer análises do micro, do sujeito, para questões mais amplas sobre a epistemologia das migrações, a própria noção de integração, o direito à educação, e, também, em relação à empreitada migratória, especialmente no impacto desse processo para as crianças.

O grupo DIASPOTICS - Migrações Transnacionais \& Comunicação Intercultural é vinculado aos programas de pós-graduação em Comunicação e Cultura e em Psicossociologia de Comunidades e Ecologia Social, respectivamente da Escola de Comunicação e do Instituto de Psicologia da Universidade Federal do Rio de Janeiro. A iniciativa é coordenada pelo professor Mohammed ElHajji, que leciona em ambos os programas. Sua finalidade é a de analisar, apreender e compreender o fenômeno migratório e diaspórico a partir dos fluxos e rastros produzidos pelas comunidades diaspóricas e pelos indivíduos migrantes, assim como através de sua mediação pelas tecnologias de informação e comunicação.

Nossa equipe conta com mestrandos, doutorandos e pós-doutorandos das áreas de Comunicação, Psicologia e Educação. A temática da migração dos equatorianos na cidade do Rio de Janeiro tem relação direta com as pesquisas e as reflexões desenvolvidas pelos componentes do grupo, que observam e promovem ações junto a essa comunidade.

A literatura sobre as migrações de equatorianos para o Rio de Janeiro é muito escassa. Faz-se importante destacar o trabalho de Vieira (2013), dissertação de mestrado em Geografia que investiga empiricamente esse grupo tão presente no comércio de rua da cidade. Fazemos nossas as palavras da autora, que defende a necessidade de novas pesquisas de campo, para tornar possível compreender de forma mais aprofundada a comunidade em questão. Buscamos realizar uma revisão da literatura sobre educação e integração de crianças imigrantes no Brasil e, particularmente, no Rio de Janeiro. Porém, o que percebemos é uma carência de estudos que tratem desta temática. Em relação aos andinos, há produções sobre a recepção de estudantes bolivianos na educação básica de São Paulo, às quais retornaremos mais adiante.

Com relação a crianças provenientes de origens culturais estrangeiras, destacamos dois trabalhos. Em primeiro lugar o estudo de Russo, Mendes e Borri-Anadon (2020), realizado com crianças de origem congolesa e angolana 
numa escola pública do Ensino Fundamental I da cidade de Duque de Caxias, na Baixada Fluminense do Rio de Janeiro. As pesquisadoras relatam que o contato entre essas crianças e as brasileiras resultou em casos de racismo, preconceito e discriminação, principalmente pelo tom de pele escuro e dos penteados diferentes usados pelas crianças estrangeiras. Essas consequências negativas da recepção de alunos em situação de migração e refúgio chamaram atenção dos docentes para discussões sobre a história e a trajetória dos novos alunos, resultando no projeto "Tudo bem ser diferente", iniciativa que debateu a diversidade no ambiente escolar (Russo, Mendes e Borri-Anadon, 2020, p. 267-269).

Também trazemos o trabalho de Souza e Roldão (2019), no qual as autoras contam sobre o projeto de extensão "O Haiti é aqui: aprendendo juntos", de acolhimento de crianças haitianas em quatro escolas municipais de Joinville, Santa Catarina. Segundo as pesquisadoras, com a meta de inserir essas crianças e adolescentes migrantes no ambiente escolar: os docentes foram treinados para lidar com a diferença em sala de aula; as circulares para os familiares passaram a ser em português e, também, em créole haitiano; a comunicação visual das escolas se tornou multilíngue; além de serem organizadas rodas de conversa para que os próprios alunos pudessem compartilhar suas experiências e sua visão sobre o processo de participação na escola.

A metodologia utilizada para o desenvolvimento deste estudo é de cunho qualitativo, reconhecendo os diálogos construídos nas interações entre os pesquisadores e os imigrantes como dados de pesquisa. Nas atividades desenvolvidas com as crianças, existe uma interação com as mães que ficam sempre trabalhando próximo do local onde o grupo de crianças está reunido com os pesquisadores. Também são tratados como dados os diálogos compartilhados nas interações criadas por meio do aplicativo de mensagens WhatsApp, onde há comunicação entre as mães, as crianças e uma pesquisadora. Todas as atividades são registradas no caderno de campo, além de eventualmente serem gravadas em vídeo e ou em áudio. O material produzido no trabalho de campo nos permite analisar as interações realizadas e compreender os processos de participação dessas crianças nas escolas, bem como os sentidos compartilhados com suas famílias a respeito do espaço escolar.

A evolução do trabalho de campo viabilizou estabelecer uma relação de confiança com o grupo pesquisado e uma ambiência propícia ao desenvolvimento da pesquisa. A familiaridade criada entre os migrantes e os pesquisadores caracteriza a entrada não invasiva de cientistas sociais no contexto onde ocorre o trabalho de campo (Martins, 2006). O percurso metodológico foi planejado buscando uma abordagem por meio da qual fosse possível compreender os sujeitos pesquisados de maneira minuciosa, onde consideramos as narrativas, os gestos e os sentimentos envolvidos neste contexto 
de produção de dados. Consideramos que, nos diálogos compartilhados no aplicativo Whatsapp, os participantes do estudo se expressam livremente. Isso permitiu entender algumas situações particulares de determinadas famílias.

Inicialmente apresentaremos nosso trabalho de mediação entre as crianças equatorianas, suas mães e os educadores da rede pública que lidam com os pequenos em questão, trazendo depoimentos e narrativas das diferentes partes envolvidas. Em seguida, desenvolvemos o conceito de integração, defendendo que deve ser um processo inclusivo e não normativo, e a sinergia que essa noção deve ter com o espaço da escola, local da diversidade, de diferentes visões de mundo e de diferentes perspectivas. Finalmente, apresentamos e discutimos as diretrizes legais relativas à educação de crianças migrantes no Brasil, assim como os desafios à aplicação prática dessas leis e à adaptação de alunos de origem equatoriana a esse sistema, intrínsecos a algumas lacunas na formação dos professores da educação básica.

\section{Falando com o coração: mães equatorianas e participação no espaço escolar}

A fala que trazemos como epígrafe deste trabalho foi motivadora de sua escrita, por conta da angústia vivida ao presenciar o diálogo entre um menino de sete anos e sua mãe, após ouvirem da professora, na escola, que a dificuldade no processo de aprendizagem da leitura em português tinha uma única causa: a mãe falar espanhol com a criança. Como não usar sua língua materna ao falar com seu filho? Como esquecer sua língua quando "fala com o coração" ao se dirigir a ele? Essas perguntas da mãe equatoriana se juntaram às nossas inquietações que surgiram bem antes, durante a pesquisa de campo.

A escolha pela inclusão do papel das mães no acesso à educação das crianças equatorianas se justifica porque foi estabelecida uma relação principalmente com essas mulheres, no início do trabalho voluntário na Praia de Copacabana. São elas que cuidam dos filhos, organizando o dia a dia dos pequenos entre a casa e a escola. Algumas conversas trazem à tona a prática cotidiana dos casais, quando elas afirmam que sempre "fazem tudo sozinhas", apesar de serem casadas. Certa ocasião, em um diálogo com Juliana² (casada com um equatoriano e mãe de dois filhos), perguntamos sobre a divisão de tarefas em casa, pois ela afirmava que estava muito cansada e não conseguia fazer os deveres da escola com os filhos. Sua resposta, depois de uma risada nervosa, foi:

Ele não me ajuda em nada... não tenho ninguém para dividir... Ele é homem e quem precisa fazer tudo sou eu... ele só fez os filhos, porque eles são assim... Mas

$\overline{2}$ Os nomes usados no trabalho são fictícios, na intenção de preservar as identidades dos participantes. 
ainda é melhor do que meu primeiro marido porque não me bate e não deixo ele bater nas crianças. Eu queria poder ter alguém para fazer coisas comigo, falar das crianças... Se eu falar que a professora reclamou deles ele só pensa em bater... aí não falo nada... é melhor assim.... Vou fazendo do meu jeito.

As narrativas das mães trazem sentimentos de contrariedade e insatisfação em relação à maneira como são tratadas na escola, à falta de orientações mais claras nas reuniões de pais e com relação à forma como as observações são feitas quando se trata do desenvolvimento das crianças. Segundo elas, é comum ouvir que seus filhos não aprendem a ler porque a família "fala muito espanhol" (observação de uma professora). Apesar de não compreenderem a língua e as orientações dadas pelas educadoras, fazem a opção de ficar em silêncio, pois não se sentem encorajadas a fazer perguntas.

Em contrapartida, parece que o desejo de falar sobre essas inquietações e angústias torna-se mais forte naqueles momentos em que essas mulheres "invisíveis" no espaço escolar se sentem encorajadas pelas conversas informais que acontecem na praia, durante seu período de trabalho. O sentimento externado remete a um silenciamento simbólico, extremamente violento no sentido subjetivo, pois nega para as mães e para as crianças um lugar de fala, de reconhecimento, de dialogicidade e alteridade, tão importantes nos processos que envolvem a construção das narrativas (Bakhtin, 2003).

Algumas crianças desenvolvem comportamentos de reclusão e não envolvimento nas atividades diárias propostas pela professora, e na maior parte das vezes essas crianças são tratadas como "crianças com dificuldades" ou "crianças desobedientes". Isso nos parece reafirmar o silenciamento que se pratica com crianças e familiares, em virtude do distanciamento que a escola assume em alguns casos. Negar a existência de uma cultura e uma língua materna é violentar simbolicamente essas famílias, de maneira a aumentar a dificuldade de adaptação e de integração no novo grupo social para onde as crianças são trazidas. Percebe-se que, subjacente ao prazer de ir à escola relatado pelos pequenos, eles também enfatizam, em suas falas, as dificuldades que encontram no cotidiano escolar. Especialmente quando se deparam com atitudes de xenofobia e preconceito, ainda que usualmente desconheçam o significado das palavras usadas pelos agressores.

Destacamos a fala de uma menina equatoriana de 6 anos, ao ser questionada sobre a escola onde estuda:

Eu gosto de ir na escola, de ficar no cantinho da leitura, de lanchar... Mas não sei as letras todas, aí a professora grita comigo e fala que é tudo feio, que sou burra... Aí fico com dor de cabeça... Mas eu não sei... tampoco me lembro de letras solamente sei mi letra, de mi madre, de mi padre... ah, também de "But" e Leandro! Só isso... (Naomi, 6 anos) 
A criança afirma que sabe algumas letras, e todas as que conhece são referentes aos nomes de familiares (But é o apelido do seu avô materno, e Leandro é o seu irmão). No entanto, a professora parece desconsiderar a construção de conhecimentos e o momento de aprendizagem em que ela se encontra. Em uma reunião na escola, perguntamos se a professora sabia a origem de Naomi e das expressões que usava em sala de aula, mas a educadora respondeu afirmando que ali só se falava português e que agora também estudavam inglês. Por isso, não poderia "perder tempo" com explicações a respeito da língua de cada criança estrangeira que estiver estudando na classe.

Dessa maneira, nosso trabalho vem se estruturando de forma a orientar e colaborar também - ainda que tenhamos limitações - com os professores dessas crianças que participam das atividades na Praia de Copacabana. Durante o ano de 2019 tivemos algumas oportunidades de atuar, por meio de palestras e cursos em espaços de formação inicial e continuada de professores, a convite de outras instituições. Em nosso entendimento, isso fomenta a discussão sobre a integração de crianças migrantes em espaços educacionais no Rio de Janeiro, importante caminho para debater e pôr em execução ações práticas nesse sentido.

Consideramos que esta proposta de agir empiricamente com as crianças migrantes se configura como uma maneira potente de resistência de garantia do direito à educação de qualidade, assim como da permanência na escola pública, de uma maneira verdadeiramente inclusiva. Compreendemos, também, a educação como direito humano e social que está presente em diferentes textos legais que abordam a educação pública para estrangeiros no Brasil.

Partindo desses pressupostos, ampliamos o escopo de ação ao incluir as mães como personagens participantes deste cenário, pois entendemos que a formação das palavras e das enunciações está imbricada na fala do outro (Bakhtin, 2003). Nesse sentido, para que haja uma construção de palavras próprias, é preciso estar inserido em um espaço que propicie vivências estimuladoras do diálogo.

A inserção do DIASPOTICS neste grupo de equatorianos trouxe a possibilidade do compartilhamento de experiências que essas mães narram com seus filhos, ao abordarem temas da vida como imigrante e, assim, nossa compreensão da realidade vivida por eles se tornou um processo contínuo de aprendizagem. A relação com a escola se estabeleceu a partir do pedido das mães para que fosse disponibilizado um intérprete nas reuniões com as professoras, assim como nas situações em que elas necessitam buscar algo junto à escola e/ou à Coordenadoria Regional de Educação da Secretaria Municipal de Educação do Rio de Janeiro. 
A escola é um espaço extremamente importante na construção de conhecimentos e na criação de experiências que propiciem o desenvolvimento cognitivo das crianças. Seu potencial transformador é reconhecido pelos autores deste texto, bem como suas possibilidades para inserção de novas práticas em consonância com os desafios que se apresentam, incluindo a diversidade dos estudantes, cada vez mais intensa no contexto brasileiro, devido às migrações transnacionais ocorridas na última década. No Ensino Fundamental, onde contextualizamos este estudo, percebemos as dimensões da formação e da construção de conhecimentos comprometidas com a remoção das diferentes formas de exclusão.

Caminhando na esteira teórica de Arroyo (2007) reconhecemos, assim como o autor, que a escola deve organizar tempos e conhecimentos, respeitando a diversidade e a especificidade de cada aluno. Isto não se trata de opção, mas cumpre uma exigência a um direito básico dos educandos. Para ele

Levando em consideração que o processo educativo é complexo e fortemente marcado pelas variáveis pedagógicas e sociais, entendemos que esse não pode ser analisado fora de interação dialógica entre escola e vida, considerando o desenvolvimento humano, o conhecimento e a cultura. (Arroyo, 1997, p. 6)

É premente trazer à tona as questões afetivas, linguísticas e legais que se apresentam no processo educativo das crianças equatorianas, considerando o fato migratório e suas implicações intrínsecas, principalmente no que tange ao acesso delas à educação. Também não podemos deixar de lado a centralidade do lugar ocupado pela criança em situação de migração, tema que tratamos na seção seguinte.

\section{Migração, integração e infância}

A palavra "imigrante" foi formada a partir do particípio latino imigrans, formado por in + migro. In é uma preposição que indica movimento de fora para dentro e migro é um verbo que se relaciona a deslocamentos de um lugar para outro. Já "imigrar", deriva do latim migrare, que significa "mudar de posição". Em muitos dos casos, podemos afirmar que o imigrante entra em um país estrangeiro buscando trabalho ou residência.

Para subsidiar nossas considerações, buscamos entender o sentido etimológico da palavra integrar. De acordo com o dicionário Michaelis, significa:

1) Incorporar(-se) um elemento num conjunto; incluir(-se), integralizar(-se);

2) Tornar(-se) adaptado a um grupo ou a uma comunidade: O professor se esforçava para integrar o novo aluno ao grupo ${ }^{3}$.

${ }^{3}$ Cf. < http://michaelis.uol.com.br/busca?id=dNMl7 >. 
Na prática, a "integração", quando alguém está se referindo a um sujeito migrante, é a forma hegemônica de tratar de um processo de chegada, entrada e gradual sentimento de pertencimento de um estrangeiro a uma comunidade onde ele é entendido como diferente e, ao mesmo tempo, experimenta os indivíduos de lá enquanto diversos dele. "Integração" não tem definição formal no Direito Internacional e, como destacam Ager e Strang (2008), pode ser um termo muito confuso, porque tenta dar conta de abarcar muitas questões intrínsecas à trajetória migratória de pessoas e de grupos específicos, usando uma única palavra.

A discussão sobre a imposição de normas e formas do que é considerado uma empreitada migratória bem-sucedida - usualmente a partir de um ponto de vista branco, ocidental e institucionalizado - a comunidades migrantes, principalmente refugiadas, não cabe neste trabalho. Portanto, para esclarecer ao leitor sobre o que estamos falando ao usar o termo "integração" para tratar dos migrantes equatorianos na cidade do Rio de Janeiro, efetivamente são as formas de propiciar ao migrante viver a realidade de um sujeito que migra e vive no Brasil.

Integrar as crianças equatorianas é fazer com que elas se sintam parte do grupo de estudantes e busquem formas de viver o cotidiano escolar, compartilhando experiências, trocando saberes e vivenciando momentos de aprendizagem. Para tanto, é necessário levar em conta a dinâmica entre dois lados envolvidos nessa questão: por um lado, o sistema de educação brasileiro, com aulas ministradas em português, professores e alunos majoritariamente brasileiros e lusófonos. Por outro, as crianças equatorianas e suas famílias, que apresentam especificidades intrínsecas ao projeto migratório do qual fazem parte, a exemplo do bilinguismo e de seus referenciais culturais específicos. A participação desses indivíduos pode ser estimulada por meio de um processo de diálogo, no qual as diferenças culturais de ambos os lados são conversadas e desmistificadas; e inclusivo, com a diversidade tratada como potência e oportunidade de troca e aprendizado entre os sujeitos envolvidos nesse contato.

As crianças que fazem parte das famílias migrantes são forçadas a deixar seus lares e seus amigos, bem como suas raízes, em função da busca que a família empreende por um país "melhor" e com mais oportunidades. É importante ressaltar que os adultos da família raramente consultam a opinião das crianças no processo de decisão de uma empreitada migratória. Todavia, ainda que possa haver condição de provisoriedade, migrar se torna, em muitos casos, algo definitivo na vida dos pequenos:

Lá no Equador está minha avó, os bichos, o jardim... Um dia vou voltar lá, mas quero ir com meus pais... Eles falam que vão me deixar lá com minha vó porque aqui tem muito tiro e não dá pra sair pra escola. Lá também tinha um amigo que 
brincava comigo, mas ele mora lá em San Pablo $^{4} .$. Eu lembro de umas coisas... outras eu esqueci... Lá não tinha tiro... e ninguém falava que eu tenho nome estranho... (narrativa de Sissi, 8 anos)

As crianças são mais vulneráveis no processo migratório e necessitam de auxílio específico em sua integração. As dificuldades encontradas são inúmeras, a começar pelas barreiras linguísticas e por questões de cunho emocional (discriminação pelas outras crianças, em função de visões estereotipadas e padrões culturais). A saudade da sua pátria, bem como a busca pelo pertencimento ao Brasil trazem implicações que influenciam o desenvolvimento emocional e cognitivo das crianças, e, consequentemente, sua adaptação ao contexto escolar local.

Sisi, uma menina de apenas oito anos, expõe algumas dessas questões ao falar sobre importantes elementos constitutivos do seu sentimento de pertencimento, como por exemplo os animais que tinha no Equador ou o jardim onde brincava e que constituía parte de sua paisagem espacial e afetiva. Ela também traz à tona na fala sua separação de pessoas queridas, causada pela empreitada migratória de sua família. Do ponto de vista da discriminação e de uma certa marginalização, emergem no relato respectivamente o estranhamento das crianças brasileiras com o seu nome, além dos tiroteios, parte do cotidiano dos moradores de favelas no Rio de Janeiro.

O caso de Sisi, destacado brevemente aqui, infelizmente é reflexo de uma forma de recepcionar crianças migrantes na escola, sem criar um processo de integração. De 2008 a 2016, o número de estudantes estrangeiros matriculados nas escolas brasileiras cresceu de 34 mil para 72 mil alunos (Souza, 2018). Desse montante, a maioria, $64 \%$, foram acolhidos pela rede pública de ensino e $40 \%$ do total são estudantes de origem latina (Souza, 2018).

Liberato e Lokoi (2014) apontam questões importantes no que diz respeito ao caso da recepção de crianças bolivianas na rede pública de ensino de São Paulo. As autoras defendem que não há apenas um estranhamento em relação aos hábitos e às feições indígenas dos bolivianos, mas também um desconhecimento da história do grupo, bem como existem questões emblemáticas que devem ser revistas acerca dos currículos e do projeto pedagógico das escolas, de maneira a mobilizar para aprendizagem todos os estudantes, independente da nacionalidade.

Com relação à integração de crianças na escola, Pieroni, Fermino e Caliman (2014, p. 73), trazem reflexões que denominam como "Pedagogia da Alteridade", buscando inspirar metodologias dialógicas para lidar com a diversidade cultural tão intensamente presente nas escolas brasileiras.

${ }_{4}$ Ao falar em San Pablo, ela se refere a São Paulo, onde estão vivendo amigos equatorianos. 
O percurso que leva à construção da identidade em qualidade de "cidadãos do mundo" passa, inevitavelmente, pela integração das pluripertenças, e não de sua subtração; isto comporta submeter à crítica os elementos irracionais que consideram básico somente o laço étnico e territorial-nacional. É necessário, por isso, procurar educar esse "cidadão do mundo" a construir uma identidade capaz de enfrentar o pluralismo sem medo do outro.

Entendemos que o aprofundamento dessas questões está entrelaçado com as histórias que o grupo DIASPOTICS tem vivenciado com essa comunidade proveniente do Equador, e buscamos construir reflexões que possam contribuir com a integração das crianças no cotidiano escolar. Nesse sentido, remetemos à narrativa de outra criança equatoriana, um menino de 11 anos, matriculado em uma das escolas de Copacabana:

Lá em Otavalo, eu ia caminhando para a escola, minha mãe me esperava com minha irmã e depois ela cozinhava. Depois eu dormia, depois de dormir eu fazia as tarefas com minha mãe... Também cuidava dos animais e ajudava minha mãe com as plantas... Tem montanhas perto da minha casa... Aqui vamos à casa do Pedro ${ }^{5}$ mas não tem as coisas que minha mãe quer cozinhar e na escola eu gosto da comida... gosto do recreio, de jogar bola, mas não gosto quando ficam rindo e dizem que não sei falar... eu sei falar e você me entende... Então por que é tão difícil com eles? A professora não me entende, por quê? Ela fica dizendo que não sei fazer nada...Mas eu não compreendo o que está escrito ali e daí vou perguntar... Mas ela não gosta e manda sentar...y creo que me entiendes.

O menino, em sua fala, faz uma comparação entre a vida levada no Equador, a rotina que tinha a escola como parte constituinte do seu cotidiano, e sua experiência no Brasil. Primeiramente, são destacadas lembranças do país. A comida, o contato com a natureza, com as plantas, com os animais e a relação com a mãe e a irmã. Em seguida, já se referindo ao Rio, além de já não ser sempre possível sua mãe encontrar os condimentos para os alimentos cozinhados outrora no Equador, é presente no relato a forma como os colegas da escola e a professora lidam com a criança.

Podemos inferir que existem algumas dificuldades de compreensão da realidade social e afetiva desse estudante por pessoas que atuam no ambiente escolar. Por parte da professora, que mostra falta de sensibilidade para com as diferenças culturais do aluno e com as dificuldades de aprendizado que apresenta. E isso também é algo presente em alguns dos outros estudantes, os que caçoam dos deslizes cometidos pelo menino quando se utiliza da modalidade falada da língua portuguesa.

Julgamos pertinente destacar novamente a epígrafe deste texto, que contém a seguinte afirmação, feita por um menino equatoriano de sete anos: "Eu vou para o Equador, deixar o cabelo crescer, e lá eu vou aprender a ler".

\footnotetext{
5 Aqui ele se refere a uma loja chamada Casa Pedro, onde a mãe procura por temperos e condimentos que costuma utilizar ao cozinhar no Equador.
} 
Na frase são evidenciados dois pontos que são afetados por conta de sua vida no Brasil: o letramento e a estética de seu cabelo.

Sobre o letramento, ele está em uma situação de bilinguismo. O menino tem convivência principalmente com o espanhol em seu convívio familiar e na comunidade equatoriana. Por outro lado, precisa aprender o português como suporte linguístico na escola e para a sua convivência no cotidiano brasileiro. Falar que quer ir para o Equador para aprender a ler expressa uma vontade de poder aprender a ler em espanhol, língua falada por sua mãe com ele, como foi exposto anteriormente.

Em relação ao que a criança diz sobre o corte de cabelo, se trata de uma diferença cultural entre o Brasil e o Equador. Muitos homens equatorianos de origem étnica indígena deixam seus cabelos crescerem, e isso é um motivo de orgulho entre eles, uma de suas marcas identitárias. Para os brasileiros, no senso comum, ter o cabelo grande é algo "de menina", o que pode causar estranhamento para algumas pessoas, assim como possíveis repreensões ou brincadeiras. Por conta disso, o menino se refere à possibilidade de deixar o cabelo crescer se estiver morando no Equador.

Grande parte dos estudantes se isola ao sofrer discriminação, e acaba por se excluir dos processos coletivos de aprendizagem e por se colocar à margem de uma nova rede de relações. É necessário que as crianças sejam estimuladas a refletir sobre as diferenças, a fim de compreender as particularidades das pessoas em seu entorno, para assim aprender a participar de uma relação de respeito mútuo desenvolvida entre os diferentes grupos que a escola recebe.

Percebemos que a cultura das crianças migrantes não é tratada de forma inclusiva e construtiva. Assim, se torna mais difícil que os outros estudantes possam reconhecer aspectos importantes das identidades desses colegas ou entender outras culturas em sua diversidade. Para Didi-Huberman e Giannari (2018, p. 59), os movimentos de migração têm um nome genérico: cultura. Não a cultura dos "Ministérios da Cultura", mas a cultura no sentido antropológico, que diz respeito ao modo como seres humanos falam, trabalham e inventam utensílios, produzem obras de arte, vivem em sociedade. Para os autores, a falta de compreensão desses aspectos leva os homens a perderem sua cultura, sua própria capacidade de civilização.

\section{Legislação brasileira sobre o acesso à educação para estrangeiros e a formação dos professores}

Consideramos que o direito à educação pública para as crianças equatorianas é parte importante de seu processo de integração ao Brasil. Nesta seção do artigo reunimos algumas das diretrizes legais intrínsecas a este tema e à atuação do DIASPOTICS junto ao referido grupo de migrantes. 
Conhecida como Lei de Migração, a Lei no 13.445/2017 (Brasil, 2017) trata o processo de legalização do imigrante, repudiando a discriminação e a xenofobia. O que podemos ver na prática é que a lei, na maior parte dos casos, não é conhecida pelo imigrante. Nas escolas ainda há desconhecimento e preconceito em virtude da falta de informação e da falta de uma formação adequada dos profissionais da educação para um momento no qual mudanças significativas ocorrem nas escolas públicas, em virtude da necessidade de acolhimento desses estudantes.

Também podemos citar o desconhecimento, por parte desses profissionais, da legislação pertinente ao caso de crianças indocumentadas, para as quais a lei prevê uma equivalência de estudos/série. Em se tratando das escolas municipais, a Deliberação E/CME no 28, de 29 de novembro de 2016 (Rio de Janeiro, 2016) divulga procedimentos para atendimento aos refugiados no Sistema Municipal de Ensino do Rio de Janeiro. Porém, em alguns casos, a equipe responsável por realizar a matrícula desse estudante desconhece os procedimentos legais e os direitos do imigrante. Do documento citado destacamos que o refugiado usufrui do mesmo tratamento oferecido aos nacionais, tem direito à adaptação de estudos e o corpo técnico-pedagógico da instituição deve estabelecer estratégias adequadas para "suprir as necessidades do aluno refugiado, assim como dos procedentes de outros países" (Rio de Janeiro, 2016, Artigo 5ㅇ), "concentrando esforços na aprendizagem da Língua Portuguesa" (Idem., Artigo 6o), para que esses alunos possam compreender as demais disciplinas.

Na Lei de Diretrizes e Bases da Educação (Brasil, 1996), o direito à educação é citado, porém a criança imigrante não é considerada com suas particularidades. A lei reafirma questões abordadas neste texto no que diz respeito aos direitos das crianças, ao incluir (Art. 3ํ) que o ensino será ministrado com base em diferentes princípios, e, dentre eles: a igualdade de condições para o acesso e permanência na escola; a pluralismo de ideias e de concepções pedagógicas e o respeito à liberdade e apreço à tolerância. Parece incoerente imaginar uma escola que não siga esses princípios quando realiza a matrícula de alunos imigrantes com diferentes origens, histórias e saberes. No entanto, na prática cotidiana de algumas escolas do Rio de Janeiro, essa não é a realidade.

Caminhando na mesma direção, destacamos o Decreto no 6.729 de 12 de janeiro de 2009 (Brasil, 2009), que promulgou o Protocolo de Integração Educativa e Reconhecimento de Certificados e Estudos de Nível Fundamental e Médio Não-Técnico entre os Estados Partes do Mercosul - Bolívia e Chile, assinado em 5 de dezembro de 2002. Consideramos de extrema importância ressaltar que o Equador não é signatário deste acordo cultural. Na prática, isto se reflete diretamente na maneira em que os estudantes indocumentados são 
recebidos e desrespeitados na sua condição de imigrantes. O que está previsto nesses casos - respaldados pela legislação vigente - é uma avaliação que deve ser feita pelas Coordenadorias Regionais de Educação, que tem por finalidade o encaminhamento do estudante para a série/ano adequado.

Por último, encontramos na Resolução no 169 do Conselho Nacional dos Direitos da Criança e do Adolescente, de novembro de 2014, que crianças e adolescentes devem ser tratados de forma cuidadosa e sensível, levando-se em consideração, entre outras, particularidades como o status de refugiado ou imigrante. O documento estabelece que os profissionais responsáveis pelo atendimento de crianças e adolescentes considerem essas diferenças, assim como com as demais especificidades inerentes à matéria.

Consideramos como uma hipótese que o desconhecimento da legislação, aliado à falta de formação docente em respeito à diversidade, cria condições para que ocorram equívocos no tratamento desses estudantes e ruídos na comunicação entre a equipe da escola, as crianças e suas mães. Dessa forma, a imigração é tratada como um problema social, ou como uma questão oriunda da relação entre um grupo social e suas tensões (os imigrantes e a questão do emprego/desemprego, a habitação, os filhos, bem como sua formação, os direitos) e, dessa maneira, são construídas as "representações coletivas" sobre a imigração e o imigrante (Sayad, 1998, p. 56).

Nossa abordagem dos aspectos legais relativos ao direito à educação de migrantes torna claro que, embora a legislação assegure o direito dessas pessoas à educação, as crianças migrantes e refugiadas sofrem pela falta de um planejamento pedagógico coerente com suas necessidades específicas. Mesmo quando essas pessoas conseguem a matrícula na escola, na maior parte das vezes não possuem professores com formação adequada para realizar o atendimento aos seus casos.

Nos parece evidente que muitos desses estudantes não são acolhidos verdadeiramente e, sem terem tido a formação necessária, os docentes não conseguem desenvolver um trabalho que proporcione aprendizagem por meio da construção de conhecimentos (Rodrigues, 2016) considerando as diferenças culturais e de linguagem.

No que tange aos docentes, entendemos que eles precisam de formação específica para atender diferentes demandas que a escola apresenta na atualidade e, dentre elas, a educação intercultural. Nesse sentido, o trabalho docente, cada vez mais complexo, precisa também compreender a formação dos discentes para um mundo em transformação e com uma grande diversidade de culturas que não devem se caracterizar como excludentes. Nesse sentido, concordamos com Souza e Senna (2016, p. 60) quando os autores afirmam que o professor reconhece seu papel social, porém, algumas 
vezes não está preparado para determinadas ações educativas e, além disso, convive com uma pluralidade de questões no cotidiano escolar. Entendemos que cada estudante carrega uma realidade diferente, com uma história distinta, o que exige um posicionamento do docente que o recebe. Muitas vezes isso representa uma dificuldade para o docente que não consegue aliar formação teórica e metodológica com estratégias didáticas para ressignificar suas práticas nesse contexto de múltiplas aprendizagens.

A realidade do trabalho desenvolvido na maior parte das escolas públicas brasileiras ainda não contempla a diversidade linguística, ampliada sobremaneira pela imigração transnacional e, no caso do Brasil, imigrantes que falam espanhol, como é o caso do grupo do qual tratamos neste estudo. A reflexão sobre teoria e prática para contextos de minoria linguística ainda não alcançou o patamar que deveria no Brasil (Souza, Senna, 2016, p. 63). Essa discussão vem caminhando lentamente nos espaços acadêmicos de formação docente. Entretanto, ainda hoje, alguns profissionais são formados sem reflexões críticas sobre as realidades que encontrarão nos diferentes ambientes de atuação.

A política brasileira para o acesso de imigrantes à educação é considerada avançada. Entretanto, apesar de haver uma "facilidade" para efetivar a matrícula de uma criança migrante em uma escola, ainda não dispomos de um sistema público de ensino - municipal e estadual - preparado para integrar esses estudantes, e nem mesmo de um planejamento pedagógico com esse fim (Oliveira, 2016). Ainda que a legislação seja clara quanto ao fato indiscutível de que as escolas precisam receber as crianças que chegam como imigrantes, não se trata apenas de recebê-los passivamente, mas sim de criar ações pontuais para integrá-los. As crianças apresentam um desenvolvimento cognitivo e emocional comprometido, e o que observamos na prática é que a legislação obriga as escolas a receberem os filhos de imigrantes em virtude do direito universal. Entretanto, as crianças estrangeiras em geral acabam não vivenciando um processo bem-sucedido de integração no meio educacional.

Segundo Magalhães (2010), precisamos compreender os aspectos envolvidos na educação dos imigrantes, como o silêncio e a timidez dos estudantes, que passam muitas vezes por "invisíveis". A autora defende que a invisibilidade desses estudantes pode se relacionar com a questão da ilegalidade, pois alguns deles buscam se proteger. Mas, além disso, há uma tendência das pessoas em não os enxergar, apesar de conviverem no mesmo bairro ou na mesma escola. Nesse sentido, a escola brasileira insere o estudante no contexto escolar. No entanto, pouco promove a aprendizagem e a promoção dos direitos humanos, o que possibilita o aparecimento de inúmeros relatos de preconceito, discriminação e violência. 
A escola deve ser um espaço onde os estudantes sejam estimulados a refletir sobre as diferenças e a compreender as particularidades dos diferentes grupos que estão ali inseridos, pois grande parte dos estudantes acaba por se isolar quando sofre reiteradamente a experiência da discriminação. Por sofrer preconceito, muitos passam a se excluir dos processos coletivos de aprendizagem, se colocando à margem de um grupo social no qual deveriam ser incluídos, com a finalidade de criar redes de relações.

\section{Considerações finais}

Este artigo teve como objetivo a reflexão sobre o direito à educação e o processo de integração de crianças migrantes se utilizando, como pano de fundo, da atuação do grupo DIASPOTICS - Migrações Transnacionais \& Comunicação Intercultural, da UFRJ, com migrantes equatorianos na Praia de Copacabana. As migrações, as experiências dos sujeitos migrantes e sua integração interessam diretamente a equipe, dado sua constituição interdisciplinar por pesquisadores de pós-graduação que tecem reflexões sobre o tema.

O tratamento das migrações como "crise migratória" na verdade, evidencia, em diversos lugares do mundo, a falta de preparo de diferentes sociedades e indivíduos para lidar com a diferença cultural. A esse respeito, a premissa de Escudero (2017, p. 150), ao afirmar que "falar da imigração é discorrer sobre a sociedade como um todo, seja a partir de uma perspectiva histórica, seja a partir das estruturas presentes da sociedade e de seu funcionamento" se faz pertinente. Comumente percebemos, nas narrativas dos professores que atendem essas crianças, um discurso carregado de simbolismos que demonstram uma forma de enxergar este grupo como um "problema". Essa forma de agir pode ser um reflexo da formação docente, bem como da estrutura pública disponível para esse profissional realizar seu trabalho e, em última instância, do olhar do docente para o aluno culturalmente diverso.

As narrativas dos educadores eventualmente mostram um movimento de palavras e significados que constroem sentidos profundamente enraizados nos inúmeros problemas que a escola pública possui. Nesse sentido, procuramos compreender o valor das narrativas construídas pelos profissionais que trabalham com as crianças migrantes e respeitar seus saberes, na tentativa de buscar um caminho que verdadeiramente inclua essas crianças no ambiente escolar. Para esta ação, buscamos também novas formas de pensar os saberes do grupo DIASPOTICS, pois nossa intenção não é criticar a escola, mas sim estabelecer um diálogo que possibilite outras formas de pensar a educação de crianças migrantes e bilíngues. 
As falas apresentadas neste artigo também nos trazem os modos de pensar a educação a partir do ponto de vista das crianças, segundo as experiências vivenciadas por elas e pelas suas famílias. Esses indivíduos comparam o que vivem aqui com o país de origem, destacando aspectos que os envolvem, além da relação com professores e com os colegas da escola. Consideramos que o ato de narrar se torna também uma forma de protesto e desabafo que propicia aos próprios equatorianos a oportunidade de refletir sobre os sentidos daquelas experiências vividas, de rememorar sua vida no país de origem e de buscar partilhar momentos que possam ser enredados ao cotidiano escolar.

Os fluxos migratórios dos equatorianos para o Brasil ocorrem em menor número do que outros, que são mais explorados pela Academia. Estudá-los pode ser uma forma de tentar entender a visão que os brasileiros têm do Equador, do povo andino e, de maneira mais ampla, quais são seus olhares para a América do Sul. Ao mesmo tempo, também pode ser uma forma de explorar como esses migrantes são recepcionados e quais são as experiências que têm no país.

Além do que já foi colocado, consideramos que este estudo se justifica por estimular mudanças - ainda que efetivadas a longo prazo - em práticas que foram construídas nos espaços sociais. Mezzadra (2012) defende a adoção de uma postura que envolva uma "sensibilidade diferente" para olhar a questão das migrações. Isto significa olhar os movimentos e os conflitos migratórios em outros termos, que priorizem as práticas subjetivas, os desejos, as expectativas, e os comportamentos dos próprios imigrantes (Mezzadra, 2012, p. 73). Todavia, isso não significa "romantizar" a imigração, e nem desconsiderar a ambivalência dessas práticas ou suas subjetividades.

Compreendemos que, no cenário descrito neste trabalho, é imprescindível adotar, no processo educativo, práticas dialógicas que levem em consideração o respeito à diversidade cultural e a construção de conhecimentos para todos os sujeitos envolvidos. Ressaltamos, ainda, que a formação docente deve contemplar essa temática, bem como suas particularidades no que tange à aprendizagem e à participação dos alunos migrantes na sala de aula. Consideramos que tal perspectiva pode propiciar maior aproximação com as crianças estrangeiras e suas famílias, para que sejam construídas interações que estimulem a integração no ambiente escolar.

\section{Referências bibliográficas}

AGER, Alastair; STRANG, Alison. Understanding integration: a conceptual framework. Journal of Refugee Studies, v. 21, n. 2, p. 166-191, 2008. Disponível em: <https://academic.oup.com/jrs/article/21/2/166/1621262>. Acesso em: 10.04.2018. 
ARROYO, Miguel G. Indagações sobre o Currículo - educandos e educadores: seus direitos e o currículo. Brasília: Ministério da Educação, Secretaria da Educação Básica, 2007. Disponível em: <http://portal.mec.gov.br/seb/arquivos/pdf/ Ensfund/indag2.pdf>. Acesso em: 16.09.2019.

BAKHTIN, Mikhail. Estética da Criação Verbal. São Paulo: Martins Fontes, 2003.

BRASIL. Conselho Nacional da Criança e do Adolescente. Resolução n. 169, de 13 de nov. de 2014. Disponível em: <http://www.in.gov.br/materia/-/asset_ publisher/Kujrw0TZC2Mb/content/id/30167846/do1-2014-12-10-resolucao-n169-de-13-de-novembro-de-2014-30167838>. Acesso em: 11.01.2020.

BRASIL. Decreto-lei no 6.729, de 12 de janeiro de 2009. Disponível em: < http:// www.planalto.gov.br/ccivil_03/_Ato2007-2010/2009/Decreto/D6729.htm > . Acesso em: 11.10.2020.

BRASIL. Lei $n^{O}$ 9.394, de Diretrizes e Bases da Educação, de 20 de dezembro de 1996. Poder Legislativo, Brasília, DF, 20 dez. de 1996. Disponível em: < http:// www.planalto.gov.br/ccivil_03/LEIS/L9394.htm>. Acesso em: 11.01.2020.

BRASIL. Lei $n^{\circ}$ 13.445, Lei de Migração. Brasília, maio 2017. Disponível em: <http://www.planalto.gov.br/ccivil_03/_Ato2015-2018/2017/Lei/L13445. htm $>$. Acesso em: 10.01.2020.

DIDI-HUBERMAN, Georges; GIANNARI, Niki. Pasar, cueste lo que cueste. Valência: Asociación Shangrila Textos Aparte, 2018.

DIASPOTICS. Homepage. 2020. Disponível em: <https://diaspotics.org/>. Acesso em: 14.10.2020.

ESCUDERO, Camila. A imprensa imigrante do Rio de Janeiro. Caderno de Resumos do IV Simpósio de Pesquisa sobre Migrações. Rio de Janeiro: Escola de Comunicação - UFRJ, 2017. Disponível em: < https://oestrangeirodotorg.files. wordpress.com/2017/09/ebook-iv-simpc3b3sio-migrac3a7c3b5es-2017.pdf > . Acesso em: 11.01.2020.

INTEGRAR. In: DICIONÁRIO MICHAELIS da língua portuguesa. Uol, 2020. Disponível em: <http://michaelis.uol.com.br/busca?id=dNMl7>. Acesso em: 10.01.2020.

LIBERATO, Débora; LOKOI, Zilda Marcia Grícoli. Crianças bolivianas nas fronteiras da educação brasileira. Políticas Educativas, Porto Alegre, v. 7, n. 2, p. 155-163, 2014. Disponível em: <http://www.cosmopolis.iri.usp.br/sites/default/files/ trabalhos-academicos-pdfs/51036-207982-1-PB.pdf>. Acesso em: 11.01.2020. MAGALHÃES, Giovanna Modé. Fronteiras do Direito Humano à Educação: um estudo sobre os imigrantes bolivianos nas escolas públicas de São Paulo. Dissertação de mestrado. Universidade de São Paulo, Faculdade de Educação, São Paulo, 2010.

MARTINS, Isabel. Analisando livros didáticos na perspectiva dos Estudos do Discurso: compartilhando reflexões e sugerindo uma agenda para a pesquisa. Pro-Posições, v. 17, n. 1, p. 117-136, 2006. 
MEZZADRA, Sandro. Multidão e Migrações: a autonomia dos migrantes. Revista ECO-Pós, v. 15, n. 2, 70-107, 2012. Doi: https://doi.org/10.29146/eco-pos. v15i2.900.

OLIVEIRA, Cida de. Formar os Formadores. Rede Brasil Atual. 2016. Disponível em: < https://oestrangeiro.org/2016/02/29/formar-os-formadores/>. Acesso em: 10.01.2018.

PIERONI, Vittorio; FERMINO, Antonia; CALIMAN, Geraldo. Pedagogia da Alteridade: para viajar a Cosmópolis. Brasília: Liber Livro, 2014.

RIO DE JANEIRO (Cidade). Deliberação $n^{O}$ 28, de 29 de novembro de 2016. Conselho Municipal de Educação. Poder Executivo, Rio de Janeiro, RJ, 29 de novembro de 2016. Disponível em: <http://www.rio.rj.gov.br/ dlstatic/10112/9129515/4240222/DELIBERACAOn3230052019.pdf>. Acesso em: 11.01.2020.

RODRIGUES, Leda. Crianças Imigrantes enfrentam a barreira da língua e despreparo da rede de ensino. Grupo de Estudos Comunica, 2016 Disponível em: < http:// grupodeestudoscomunica.blogspot.com.br/2016/02>. Acesso em: 11.01. 2020.

RUSSO, Kelly; MENDES, Leila; BORRI-ANADON, Corina. Crianças em Situação de Imigração na Escola Pública: Percepções de Docentes. Cadernos de Pesquisa, v. 50, n. 175, p. 256-272, 2020.

SAYAD, Abdelmalek. O que é um imigrante. In: SAYAD, Abdemalek. Imigração ou os paradoxos da alteridade. São Paulo: EDUSP, 1998.

SOUZA, Janaína Moreira P.; SENNA, Luiz Antonio Gomes. Desafios para inclusão de imigrantes em escolas de regiões fronteiriças. Textos e Debates, n. 30, p. 5568, 2016.

SOUZA, Ludmilla. Estudantes imigrantes aumentam 112\% em oito anos nas escolas brasileiras. Agência Brasil, São Paulo, 05.07.2018. Disponível em: <http:// agenciabrasil.ebc.com.br/educacao/noticia/2018-02/estudantes-imigrantesaumentam-112-em-oito-anos-nas-escolas-brasileiras>. Acesso em: 10.01.2020.

SOUZA, Sirlei de; ROLDÃO, Sandra Felício. A inserção escolar de imigrantes haitianos na cidade de Joinville (SC), uma questão de direitos humanos. In: $42^{\circ}$ Congresso Brasileiro de Ciências da Comunicação - Intercom. Belém - PA, 2 a 7 de setembro de 2019.

VIEIRA, Camila da Silva. A cidade do Rio de Janeiro no contexto das migrações internacionais contemporâneas: O exemplo dos equatorianos no comércio de rua. Dissertação de mestrado. Universidade Federal do Rio de Janeiro, Instituto de Geociências, Rio de Janeiro, 2013. 